\title{
Eco-Friendly Location of Small Hydropower
}

\author{
Christina Ioannidou Jesse R. O’Hanley* \\ Kent Business School, University of Kent, Canterbury CT2 7PE, United Kingdom
}

\begin{abstract}
We address the problem of locating small hydropower dams in an environmentally friendly manner. We propose the use of a multi-objective optimization model to maximize total hydropower production, while limiting negative impacts on river connectivity. Critically, we consider the so called "backwater effects" that dams have on power generation at nearby upstream sites via changes in water surface profiles. We further account for the likelihood that migratory fish and other aquatic species can successfully pass hydropower dams and other artificial/natural barriers and how this is influenced by backwater effects. Although naturally represented in nonlinear form, we manage through a series of linearization steps to formulate a mixed integer linear programing model. We illustrate the utility of our proposed framework using a case study from England and Wales. Interestingly, we show that for England and Wales, a region heavily impacted by a large number of existing river barriers, that installation of small hydropower dams fitted with even moderately effective fish passes can, in fact, create a win-win situation that results in increased hydropower and improved river connectivity.
\end{abstract}

Keywords: small hydropower; optimization; fish passage barriers; river connectivity; backwater effects; probability chains.

\section{Introduction}

Efforts to reduce carbon emissions in both industrialized and developing countries has resulted in an increased interest in renewable energy production. Hydropower, in particular, has gained special attention. Although installation costs can be appreciable, operating costs are generally low, the technology is already well developed, and of the many other sources of renewable energy (e.g., wind and solar) it is far more reliable in terms of providing base load power generation. Among the various types, small hydropower plants (SHP)

*Correspondence email: j. ohanley@kent.ac.uk 
with an installed capacity of up to $10 \mathrm{MW}$ are by far the most common and logistically feasible option in many places, particularly across Europe. According to the European Small Hydropower Association, SHP currently supplies enough electricity for 13 million households and plays a key role in greenhouse gas (GHG) emissions reduction through green energy production (ESHA, 2012). It also supports water management policies, aids in climate change adaptation through flood control, and contributes to the prevention of water scarcity and drought.

In the UK, the government has set a goal of reducing emissions by $18 \%$ by 2020 (HM Government, 2009a). Renewable energy is considered a key part of the overall plan with respect to electricity generation. In particular, the UK Renewable Energy Strategy has set a legally-binding target to ensure that 15\% of energy production comes from renewable sources by 2020 (HM Government, 2009b). Even if small-scale hydropower is not expected to play a major role in this, the ambition is such that all sources of renewable energy are expected to deliver their maximum sustainable potential (EA, 2010). In particular, according to the UK's National Renewable Energy Action Plan (DECC, 2010), new SHP schemes of between 40 MW and 50 MW need to be installed annually until 2020 .

Although clean in terms of GHG emissions, the installation of hydropower schemes can nonetheless have adverse impact on the local environment, especially on fish populations and other aspects of river ecosystems (Stanford et al., 1996; Bednarek, 2001; Roni et al., 2002; O’Hanley and Tomberlin, 2005). Hydropower dams form physical barriers that often disrupt the natural connectivity of rivers by reducing water and sediment transfer, which can impact geomorphology processes and fragment river habitats. In particular, dams can impede fish access to essential breeding and rearing areas, resulting in reduced fish productivity and other changes in aquatic community composition (Lucas and Baras, 2001). Hence, any decision about installing hydropower dams normally involves a trade-off between renewable energy production on the one hand and healthy rivers on the other. This highlights the need for decision support tools in SHP location planning, which are capable of balancing these two basic but competing goals. Such tools would prove extremely useful to river management organizations in devising more sound and effective hydropower development strategies.

In this paper, the problem of optimally locating SHPs is addressed. We propose a series of integer programing models for siting SHPs in order to maximize overall hydropower generation capacity while limiting negative impacts on river connectivity. Studies thus far have focused on searching for a set of feasible locations for installing SHP rather than optimizing site selection. 


\section{$1.1 \quad$ Hydropower Location}

Much of the literature on hydropower location focuses on the use of geographic information systems (GIS) to screen for potential dam locations, driven in large part by the increasing availability of satellite imagery and other remotely sensed data. Site feasibility and power generation potential are usually the two main concerns (Ramachandra et al., 2004; Dudhani et al., 2006; Coskun et al., 2010; Kusre et al., 2010; Cyr et al., 2011), with only occasional treatment of environmental aspects (Lee et al., 2008; Rojanamon et al., 2009; Yi et al., 2010). A good example is the study by Yi et al. (2010), which uses a combination of hydrologic, topographic, and environmental criteria to rate the suitability of candidate SHP sites. Using a case study area in South Korea, a small set of promising locations for reservoir and run-of-river type SHPs is identified by performing a series of geospatial data processing steps.

Installation decisions are considered independently in almost every proposed methodology. An exception is Larentis et al. (2010), where the interactive effects of hydropower dams are considered. The proposed methodology treats total hydropower in a subbasin as a system, where the siting of a dam reduces the generation potential of upstream sites by raising the water surface depth (the so called "backwater" effect explained in more detail in Section 2.3). Maximum hydropower potential within a basin is estimated by siting dams in series along a river course, such that each dam lies outside the length of the backwater curve produced by the dam downstream.

Of particular relevance to our current work is the study by Ziv et al. (2012). Rather than employ a typical GIS approach, the authors examine in detail the ecological impacts of hydropower development within the Mekong River Basin. Their framework, which incorporates spatially-explicit fish dispersal and population growth models, is designed to explore trade-offs between hydropower, fish abundance, and biodiversity. Tradeoff curves are produced by enumerating all possible dam development scenarios, which invariably limits the scalability of their approach to problems involving small numbers of possible dam locations.

Another relevant study is one carried out by the UK's Environment Agency (EA), which looked into the potential for expanding renewable energy production from small scale hydropower across England and Wales (EA, 2010). All known weirs were considered as possible hydropower plant locations. Using a variety of methods to estimate flow, weirs were assessed for their hydropower potential and subsequently categorized based on their environmental sensitivities (i.e., presence of fish key fish species or areas of special conservation concern).

To our knowledge, Chang et al. (1992) is only existing example in the literature to propose a formal optimization framework for selecting hydropower development alternatives. Their methodology takes into account 
potential reductions in water quality (measured in terms of dissolved oxygen concentrations) caused by the installation of hydropower dams. Using a case study of the upper Ohio basin, they investigate trade-offs between power generation and water quality.

\subsection{Barrier Mitigation Planning}

While there are few examples involving the use of optimization techniques for locating new hydropower dams (Chang et al., 1992), optimization has been applied frequently in the context of cost-effectively removing of dams and other river infrastructure to improve river connectivity. Some examples include: Paulsen and Wernstedt (1995), O'Hanley and Tomberlin (2005), O'Hanley (2011), O'Hanley et al. (2013b), and Neeson et al. (2015). A key feature of these studies and other similar optimization based approaches is the explicit consideration of the spatial structure of barrier networks and the interactive effects that barrier removal decisions have on longitudinal connectivity.

One study dealing specifically with hydropower is Kuby et al. (2005), who propose the use of a multiobjective optimization model for prioritizing the removal of large hydropower dams. Their model quantifies trade-offs between ecological gains for migratory fish, economic losses from reduced hydropower generation and water storage capacity. The use of a multi-objective framework is noteworthy in that it offers decision makers a means of identifying alternative portfolios of dam removal that vary in terms of their ecological and socioeconomic benefits. This, in turn, can help to inform negotiations among managers and different stakeholders.

Zheng et al. (2009) propose a mixed integer linear programing model for optimizing the net benefits of removing multiple dams in the Lake Erie basin. The model is multi-objective and aims to maximize a combination of ecological (e.g., native species biomass) and socio-economic (e.g., recreational and commercial harvesting) goals subject to a budget constraint. Zheng and Hobbs (2012) extend the model proposed by Zheng et al. (2009) by adding the additional goal of reducing the risk of dam failure.

A detailed review of procedures and techniques related to evaluating and prioritizing the mitigation of fish passage barriers can be found in Kemp and O'Hanley (2010). Given multiple and often conflicting environmental and economic goals, they recommend the use of optimization models and multi-criteria decision making techniques as an objective and efficient means for prioritizing barrier repair and removal decisions.

The remainder of the paper is organized as follows. In Section 2, we present the hydropower plant location problem. Specifically, in Section 2.1, we present a basic nonlinear model and in Section 2.2 a linear reformulation. In Section 2.3, we talk briefly about the backwater effect caused by siting a dam. This is followed 
in Section 2.4 by the development of an extended version of the hydropower plant location problem, where backwater effects are considered. In Section 3, we apply our methodology to a case study of England and Wales and discuss key findings. Finally, in Section 4, we give some concluding remarks.

\section{Hydropower Plant Location Problem}

The aim of the hydropower plant location problem (HPLP) is to select sites for installing dams to maximize potential hydropower generation while keeping longitudinal river connectivity at or above some specified lower bound. Given a range of dam sizing options for each potential dam location, the hydropower potential $w_{j i}$ (measured in Watts) at site $j$ when fitted with a dam of size $i$ is defined by the well-known equation:

$$
w_{j i}=\eta_{j i} \rho g Q_{j} H_{j i}
$$

where $\eta_{j i}$ is the efficiency (in the range 0-1) of the dam's turbine, $\rho$ is the density of water $\left(1000 \mathrm{~kg} / \mathrm{m}^{3}\right), g$ is the acceleration due to gravity $\left(9.81 \mathrm{~m} / \mathrm{s}^{2}\right), Q_{j}$ is the river's volumetric flow $\left(\mathrm{m}^{3} / \mathrm{s}\right)$ at site $j$, and $H_{j i}$ is the hydraulic head $(\mathrm{m})$ of the dam (i.e., the difference in water surface height above and below a dam). At each site $j$, only one sizing option $i$ can be selected.

Hydropower dams and other artificial or natural barriers that may be present within a river network are assumed to allow partial fish passage. More formally, the passability of a barrier refers to the fraction of fish, in the range $[0,1]$, that are able to successfully navigate it in the upstream and or downstream direction, where 0 denotes a completely impassable structure and 1 a completely passable one (Kemp and O'Hanley, 2010). Typically, barriers with larger head heights are more difficult to pass as fish need to leap higher. Cumulative passability, which is synonymous with longitudinal connectivity, describes the collective impact that multiple barriers have on fish dispersal. Assuming barrier passabilities are independent, cumulative passability to an area immediately above any barrier is evaluated by multiplying the barrier's passability by the passabilities of any downstream barriers to the river mouth. To ensure that longitudinal connectivity is not excessively compromised by the installation of hydropower dams, a constraint is included in the model HPLP requiring cumulative passability weighted habitat above hydropower dams and other barriers to be greater than or equal to a user-defined threshold. For each dam sizing option, a different barrier passability value can be assigned depending on the dam's height and what options are available for constructing an effective fish pass (e.g., fish ladder, fish elevator, or bypass channel). 


\subsection{Basic Model}

In order to formulate a basic version of HPLP, let $N$, indexed by $j$, be the set of candidate hydropower dam sites. For each dam site $j \in N$, set $S_{j}$, indexed by $i$, specifies the dam sizing options available at $j$. Installation of a dam of size $i$ at site $j$ results in a hydropower potential of $w_{j i}$, as determined by equation (1). In addition to locating new dams, other artificial and natural barriers, which invariably impact fish passage and longitudinal connectivity, may already be present in a river network. These are denoted by the set $B$, indexed by $j$, while the set $J$, indexed by $j$ and $k$, is used to denote all existing artificial/natural barriers plus candidate dam sites (i.e., $J=N \cup B$ ). It is assumed throughout that a river has a strictly "dendritic" structure, meaning that it never diverges in the downstream direction, thus excluding braided river systems. In effect, this implies that 1 ) the set of potential barrier locations $J$ forms a tree network with each location $j \in J$ having at most one downstream site and 2) there is a unique path from the river mouth to any upstream location.

To continue, the set $D_{j} \subseteq J$ specifies all potential barriers downstream from and including site $j \in J$. For each location $j \in J$, the quantity $v_{j}$ denotes the net amount of habitat (measured in terms of length or area) upstream of $j$ to the next set of potential barriers or the ends of the river network. Parameter $p_{j}^{0}$ refers to the current passability of site $j \in J$, while $p_{j i}$ refers to the change in passability at site $j \in N$ when a dam of size $i$ is built there. Note that $p_{j i}$ can be negative (a decrease in passability), positive (an increase in passability), or zero (no change in passability) depending on what type of dam and or fish passage structure is installed.

This requires some further explanation. In general, installation of a dam will cause a decrease in fish passage. However, in certain situations (as with our study area discussed below), it may be feasible to locate hydropower dams at existing artificial or natural barriers, which have current passabilities well below 1 (i.e., if $N \cap B \neq \emptyset$ ). If a dam were to be located at such a site and fitted with a suitable fish pass, then it is entirely possible for passability to increase above its current baseline.

Finally, let $V^{0}$ be the total amount of habitat currently accessible to fish (i.e., $V^{0}=\sum_{j} P_{j}^{0} v_{j}$, where $\left.P_{j}^{0}=\prod_{k \in D_{j}} p_{k}^{0}\right)$ and let $\alpha \geq 0$ be a scaling parameter for determining the minimum amount of accessible habitat that needs to be achieved following the siting of hydropower dams.

Using the following decision variables:

$$
x_{j i}= \begin{cases}1 & \text { if a hydropower dam of size } i \text { is installed at site } j \\ 0 & \text { otherwise }\end{cases}
$$


$z_{j}=$ cumulative passability to river habitat immediately above location $j$

a nonlinear formulation for HPLP is given as follows:

$$
\begin{aligned}
& \text { [HPLP1] } \max \sum_{j \in N} \sum_{i \in S_{j}} w_{j i} x_{j i} \\
& \text { s.t. } \\
& z_{j}=\prod_{k \in D_{j}}\left(p_{k}^{0}+\sum_{i \in S_{k}} p_{k i} x_{k i}\right) \quad \forall j \in J \\
& \sum_{j \in J} v_{j} z_{j} \geq \alpha V^{0} \\
& \sum_{i \in S_{j}} x_{j i} \leq 1 \quad \forall j \in N \\
& x_{j i} \in\{0,1\} \quad \forall j \in N, i \in S_{j}
\end{aligned}
$$

The objective function (2) maximizes the sum of hydropower potential across all candidate dam sites. The first set of constraints (3) calculates the cumulative passability of each site $j$. Cumulative passability $z_{j}$ equals the product of the passability of site $j$ and the passabilities of all downstream sites to the river mouth. The passability of site $j$ equals initial passability $p_{j}^{0}$ plus any change in passability $p_{j i}$ if a hydropower dam of size $i$ is installed at $j\left(x_{j i}=1\right)$. Constraint (4) guarantees that total cumulative passability weighted habitat is bounded below by some multiple $\alpha$ of the current amount of accessible habitat $V_{0}$ within the study area. Constraints (5) guarantee that at most one hydropower sizing option is selected at site $j$. Finally, constraints (6) force the $x_{j i}$ dam location variables to be binary. 


\subsection{Linear Reformulation}

To reformulate [HPLP1] as a mixed integer linear program, we introduce the following additional variables:

$$
y_{j i}=\text { change in cumulative passability at site } j \text { given installation of dam size } i
$$

Variable $y_{j i}$ equals 0 if there is no change in cumulative passability at site $j$ and is positive/negative given an increase/decrease in cumulative passability. Further, let $d_{j} \in D_{j}$ refer to the potential barrier immediately

downstream of $j$, if one exists. A linear version of the basic HPLP problem can be derived by replacing equations (3) with the following constraints:

$$
\begin{aligned}
& z_{j}=\left\{\begin{array}{l}
p_{j}^{0}+\sum_{i \in S_{j}} y_{j i} \quad D_{j}=\emptyset \\
p_{j}^{0} z_{d_{j}}+\sum_{i \in S_{j}} y_{j i} \quad D_{j} \neq \emptyset
\end{array} \forall j \in J\right. \\
& y_{j i}=p_{j i} x_{j i} \quad \forall j \in N, i \in S_{j} \mid D_{j}=\emptyset \\
& y_{j i} \leq p_{j i} z_{d_{j}}-p_{j i}\left(1-x_{j i}\right) \quad \forall j \in N, i \in S_{j} \mid D_{j} \neq \emptyset \wedge p_{j i}<0 \\
& y_{j i} \leq 0 \quad \forall j \in N, i \in S_{j} \mid D_{j} \neq \emptyset \wedge p_{j i}<0 \\
& \quad \forall j \in N, i \in S_{j} \mid D_{j} \neq \emptyset \wedge p_{j i} \geq 0 \\
& y_{j i} \leq p_{j i} z_{d_{j}} \leq p_{j i} x_{j i} \quad \forall j \in N, i \in S_{j} \mid D_{j} \neq \emptyset \wedge p_{j i} \geq 0
\end{aligned}
$$

The $z_{j}$ and $y_{j i}$ variables, in combination with constraints (7)-(12), form a series of "probability chains" (O'Hanley et al., 2013a) that recursively evaluate the cumulative passability of each site $j$ based on the cumulative passability downstream from $j$. Cumulative passability is being evaluated up the point that 
constraint (4) In particular, equations (7) determine the cumulative passability for each site. There are two cases. If site $j$ has no potential downstream barrier $\left(D_{j}=\emptyset\right)$, then cumulative is equal to the initial passability $p_{j}^{0}$ at $j$ plus any change in cumulative passability $\sum_{i \in S_{j}} y_{j i}$ resulting from the installation of a dam at $j$. Alternatively, if site $j$ does have at least one downstream site $\left(D_{j} \neq \emptyset\right)$, then the initial passability $p_{j}^{0}$ at $j$ needs to be further multiplied by the cumulative passability $z_{d_{j}}$ of $j$ 's downstream site $d_{j}$.

Collectively, constraints (8)-(12) determine changes in cumulative passability $y_{j i}$ due to dam installation. If site $j$ has no potential downstream barrier $\left(D_{j}=\emptyset\right)$, equations $(8)$ simply state that the change in cumulative passability $y_{j i}$ due to the installation of a dam of size $i$ is equal to $p_{j i}$ if a dam is located there $\left(x_{j i}=1\right), 0$ otherwise $\left(x_{j i}=0\right)$. For sites with at least one potential downstream barrier $\left(D_{j} \neq \emptyset\right)$, inequalities $(9)$ and (10) apply in cases where dam installation would cause a decrease in passability $\left(p_{j i}<0\right)$, while inequalities (11) and (12) apply if dam installation would potentially cause an increase in passability $\left(p_{j i} \geq 0\right)$. In either situation, they place an upper bound of $p_{j i} z_{d_{j}}$ on variable $y_{j i}$ whenever a dam is located at site $j\left(x_{j i}=1\right)$, 0 otherwise.

It is worth pointing out that the upper bounds on the $y_{j i}$ variables imposed by (9)-(12) are not guaranteed to be strictly binding. Implicitly, there is a preference for increases (decreases) in cumulative passability to be as large (small) as possible in order to satisfy the minimum accessible habitat constraint (4) (i.e., by having the $y_{j i}$ variables equal to their upper bounds). However, in situations where the siting of dams produces a slack in constraint (4), it is possible for one or more $y_{j i}$ variables to be less than their specified upper bounds and still satisfy constraint (4). While this in no way affects the optimality of the $x_{j i}$ variables, values for the $y_{j i}$ variables and hence total accessible habitat $\sum_{j \in J} v_{j} z_{j}$ may be incorrectly specified.

To determine precisely changes in cumulative passability, one can perform a simple post-processing step, after an optimal solution for the $x_{j i}$ variables has been found, in which the $y_{j i}$ variables for sites $j \in J$ with at least one downstream barrier $\left(D_{j} \neq \emptyset\right)$ are iteratively set to $p_{j i} z_{d_{j}} x_{j i}$ starting with the most downstream sites (i.e., $\left|D_{j}\right|=1$ ) and progressively moving in the upstream direction. Alternatively, one can include a secondary objective in an attempt to force the $y_{j i}$ variables to their upper bounds. More specifically, this can be achieved by adding $\varepsilon \sum_{j \in N} \sum_{i \in S_{j}} y_{j i}$ to objective function (2), where $\varepsilon>0$ is some very small weight less than the minimum difference between any pair of hydropower potential values $w_{j i}$ (e.g., $\varepsilon=$ $\left.0.99 \times \min _{j, k \in N, i \in S_{j}, t \in S_{k}}\left\{w_{j i}-w_{k t}\right\}\right)$. In our implementation, we used the post-processing option. 


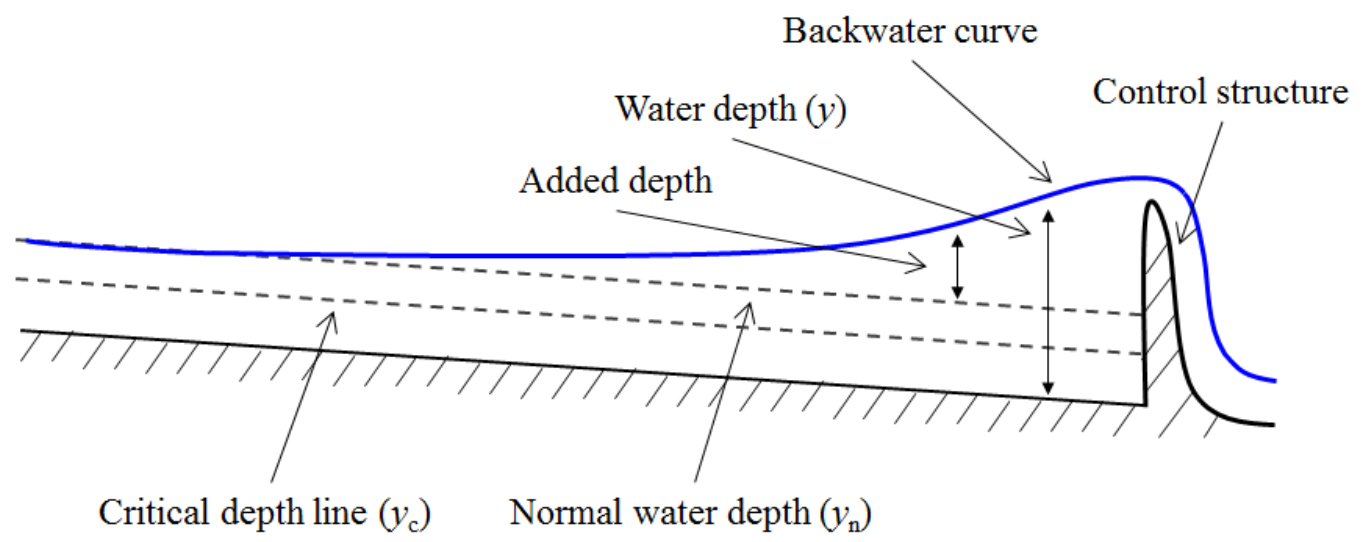

Figure 1: Representative backwater profile for a mild M1-type curve $\left(y>y_{\mathrm{n}}>y_{\mathrm{c}}\right)$.

\subsection{Backwater Effects on Hydropower Potential}

In model [HPLP1], hydropower potential at each candidate site is assumed to be independent of the spatial arrangement of dams, which does not necessarily hold in reality. In particular, the presence of a dam within a watercourse (or any in-stream structure) invariably causes an increase in the water surface behind the dam, which gradually decreases as one moves in the upstream direction (Figure 1). This change in the water surface profile of a river is called the "backwater effect" and is described by the backwater curve, which determines, based on slope and flow characteristics, the depth of water at any given point upstream.

Backwater curves are important when evaluating the hydropower potential of sites. The presence of a dam can cause a reduction in head difference (due to increased water depth) and hence a reduction in hydropower potential at upstream sites. One option for dealing with backwater effects, akin to Kusre et al. (2010), would be to include additional constraints in [HPLP1] that prevent nearby dams from being simultaneously located if and when the change in head difference at the upstream site (caused by the presence of a dam downstream) exceeds some threshold. The alternative, details of which are given below, is to explicitly incorporate backwater effects into a more realistic but complex model.

To formulate a hydropower plant location model with interactive backwater effects, consider the following additional notation. Let $M_{j}$ be the set of sites downstream from $j$ that can potentially have a backwater effect on site $j$ and let $I_{j k}=D_{j} \backslash\left(\{j\} \cup D_{k}\right)$ be the set of sites lying between $j$ and $k$. Assuming no dams are located in set $I_{j k}$ (i.e., $x_{\ell s}=0, \forall \ell \in I_{j k}, s \in S_{k}$ ), the reduction in head due the backwater effect caused by a dam of size $t$ located at downstream site $k \in M_{j}$ is denoted by $\Delta H_{j k t}$.

Given the following additional decision variables: 
$\pi_{j i}=$ hydropower potential at site $j$ given installation of dam size $i$

$$
\lambda_{j k t}= \begin{cases}1 & \text { if a dam of size } t \text { installed at site } k \text { has a backwater effect on a dam } \\ & \text { located at site } j \text { upstream } \\ 0 & \text { otherwise }\end{cases}
$$

a more general formulation of HPLP is given by:

$$
\text { [HPLP2] } \max \sum_{j \in N} \sum_{i \in S_{j}} \pi_{j i}
$$

subject to constraints (4)-(12) and the following:

$$
\begin{aligned}
& \pi_{j i} \leq a_{j i} H_{j i} x_{j i} \quad \forall j \in N \\
& \pi_{j i} \leq a_{j i} H_{j i}-a_{j i} \sum_{k \in M_{j}} \sum_{t \in S_{k}} \Delta H_{j k t} \lambda_{j k t} \quad \forall j \in N \\
& \lambda_{j k t} \geq \sum_{i \in S_{j}} x_{j i}+x_{k t}-1-\sum_{\ell \in I_{j k}} \sum_{s \in S_{\ell}} x_{\ell s} \quad j \in N, \forall k \in M_{j}, t \in S_{k} \\
& \lambda_{j k t} \geq 0 \quad N, k \in M_{j}, \forall t \in S_{k} \\
& x_{j i}+x_{k t} \leq 1+\sum_{\ell \in I_{j k}} \sum_{s \in S_{\ell}} x_{\ell r} \quad \forall j \in N, i \in S_{j}, k \in M_{j}, t \in S_{k} \mid \Delta H_{j k t} \geq H_{j i}
\end{aligned}
$$

The objective function (13), similar to (2), maximizes total hydropower potential. The difference from (2) is that hydropower is no longer fixed for each location and dam size option, hence the use of decision variables $\pi_{j i}$. Inequalities (14) and (15), in combination, determine the hydropower potential of each site $j$, where 
parameter $a_{j i}=\eta_{j i} \rho g Q_{j}$. Specifically, if no dam is located at site $j$, constraints (14) forces hydropower potential to be 0 . On the other hand, if a dam of size $i$ is located at site $j$, (15) becomes strictly binding and specifies that the hydropower potential of the dam must be less than or equal to the power that can be produced with a nominal head value of $H_{j i}$ minus any decrease in power caused by the existence of a backwater effect on site $j$ (i.e., if $\lambda_{j k t}=1$, for any $k \in M_{j}, t \in S_{k}$, a head reduction of $\Delta H_{j k t}$ occurs). Note that if $x_{j i}=1$ and there is no backwater effect on site $j$, then (14) and (15) will be binding. Constraints (16) guarantee that $\lambda_{j k t}=1$ if and only if a hydropower dam is installed at $j$, a dam of size $t$ is installed at $k$, and

no dam is installed in between them (i.e., $\sum_{\ell \in I_{j k}} \sum_{s \in S_{\ell}} x_{\ell s}=0$ ). For all other situations, constraints (17) prevent $\lambda_{j k t}$ from becoming negative. Due to the structure of the problem, the $\lambda_{j k t}$ variables are guaranteed to take on binary values. The next set of constraints (18) prevent the nonsensical siting of dams in which the installation of a dam would cause an upstream dam to become completely "swamped" (i.e., the reduction in head $\Delta H_{j k t}$ caused by a backwater effect is greater than the initial head $H_{j i}$ of the dam).

\subsection{Backwater Effects on Barrier Passability}

In the above model [HPLP2], it is inherently assumed that backwater effects only impact hydropower potential. In the majority of cases, particularly for small dams and weirs, head is also a critical factor in determining the passability of a barrier. In what follows, we present an even more general model, denoted [HPLP3], in which backwater effects can also influence the passability of barriers. To begin with, assume that passability $p_{j}$ as site $j$ is determined by the function:

$$
p_{j}=f_{j}\left(H_{j}, \mathbf{x}_{j}\right) \quad \forall j \in J
$$

where $H_{j}$ is the effective head height at site $j$ and $\mathbf{x}_{j}=\left(x_{j 1}, \ldots x_{j\left|S_{j}\right|}\right)$ specifies the vector of hydropower dam installation decisions for site $j$. Note that the $p_{j}$ variables would, in turn, influence cumulative passabilities such that $z_{j}=\prod_{k \in D_{j}} p_{k}, \forall j$. In the special case where equations (19) form a set of step-functions (e.g., equation (34) used in our case-study described below), it is possible formulate a linear model using a piece-wise linear representation of (19), as described in Winston (2004), Sec. 9.2.

Specifically, let $H_{j}^{0}$ be the initial head height for site $j$ and let $H_{j i}^{\prime}$ be the nominal increase in head height due to the installation of a dam of size $i$ at site $j$. As before, $\Delta H_{j k t}$ represents the change in head height due to the backwater effect caused by a dam of size $t$ located at site $k$ downstream. Further, let $\hat{p}_{j r}^{0}, r=1, \ldots, R$, be the nominal passability level of site $j$ when no hydropower dam is located at $j$ and head height $H_{j}$ is in 
the range $\left(\hat{H}_{r}, \hat{H}_{r+1}\right]$. Similarly, let $\hat{p}_{j i r}$ be the passability of site $j$ when a dam of size $i$ is built there and head height $H_{j}$ is in the range $\left(\hat{H}_{r}, \hat{H}_{r+1}\right]$. Note that the $\hat{H}_{r}$ define a total of $R+1$ breakpoints along the curve $H_{j}$ versus $f_{j}\left(H_{j}, \mathbf{x}_{j}\right)$. By introducing the following auxiliary variables:

$$
\begin{aligned}
& \mu_{j k t}= \begin{cases}1 & \text { if a dam of size } t \text { is installed at } k \text { and no dam is installed between } j \text { and } k \\
0 & \text { otherwise }\end{cases} \\
& u_{j r}= \begin{cases}1 & \text { if the head height for site } j \text { is in the range }\left(\hat{H}_{r}, \hat{H}_{r+1}\right] \\
0 & \text { otherwise }\end{cases}
\end{aligned}
$$

$\theta_{j r}=$ weight assigned to $r$-th breakpoint $\hat{H}_{r}$ for site $j$

$$
\psi_{j r}=\text { cumulative passability of site } j \text { given that } j \text { 's head height is in the range }\left(\hat{H}_{r}, \hat{H}_{r+1}\right]
$$

equations (19) can be replaced with (20)-(28) below.

Determination of Head Height

$$
\begin{aligned}
& \sum_{r=1}^{R+1} \hat{H}_{r} \theta_{j r}=H_{j}^{0}+\sum_{i \in S_{j}} H_{j i}^{\prime} x_{j i}-\sum_{k \in M_{j}} \sum_{t \in S_{k}} \Delta H_{j k t} \mu_{j k t} \quad \forall j \in J \\
& \sum_{r=1}^{R+1} \theta_{j r}=1 \quad \forall j \in J \\
& \theta_{j r} \geq 0 \quad \forall j \in J, r=1, \ldots, R \\
& \theta_{j r} \leq\left\{\begin{array}{c}
r=1 \\
u_{j r} \\
u_{j(r-1)}+u_{j r} \quad r=2, \ldots, R-1 \\
u_{j(r-1)} \quad r=R+1
\end{array} \quad \forall j \in J\right.
\end{aligned}
$$




$$
\begin{aligned}
& \sum_{r=1}^{R} u_{j r}=1 \quad \forall j \in J \\
& u_{j r} \in\{0,1\} \quad \forall j \in J, r=1, \ldots, R \\
& \mu_{j k t} \leq x_{k t} \quad \forall j \in J, \forall k \in M_{j}, \forall t \in S_{k} \\
& \mu_{j k t} \leq 1-\sum_{s \in S_{\ell}} x_{\ell s} \quad \forall j \in J, k \in M_{j}, t \in S_{k}, \ell \in I_{j k}
\end{aligned}
$$

Equations (20) in combination with constraints (21) and (22) simply require that a convex combination of the breakpoints $\hat{H}_{r}$ with weights $\theta_{j r}$ (the left hand side of $(20)$ ) be found which is equal to the effective head height of site $j$ (the right hand side (20)). The effective head height at site $j$, in turn, is equal to the initial head $H_{j}^{0}$ plus any nominal increase in head $H_{j i}^{\prime}$ due to the installation of a dam of size $i\left(x_{j i}=1\right)$ minus any decrease in head $\Delta H_{j k t}$ due to the backwater effect on site $j$ caused by a dam of size $t$ located at downstream site $k\left(\mu_{j k t}=1\right)$. Constraints $(23)$-(25) enforce adjacency restrictions on the $\theta_{j r}$ weighting variables, namely that at most two weights can be positive and must be adjacent. Assuming that passability and head height are inversely related, it is preferable, all things considered, for $\mu_{j k t}=1$ in order to have higher passability at site $j$ and so more easily meet the minimum accessible habitat requirement (4). Constraints (26) and (27) force variable $\mu_{j k t}$ to be equal to 0 if either no dam is located at site $k$ downstream $\left(x_{t k}=0\right)$ or a dam is installed between $k$ and $j\left(\sum_{s \in S_{\ell}} x_{\ell s}=1 \mid \ell \in I_{j k}\right)$.

Given a correct determination of the head height at site $j$, the $u_{j r}$ can be used to determine the cumulative passability of site $j$ through the use of constraints (29)-(32) below.

Determination of Passability

$$
\begin{aligned}
& z_{j}=\sum_{r=1}^{R} \psi_{j r} \quad \forall j \in J \\
& \psi_{j r} \leq \hat{p}_{j r}^{0} u_{j r}+\sum_{i \in S_{j}} x_{j i} \quad \forall j \in J, r=1, \ldots, R
\end{aligned}
$$




$$
\begin{aligned}
& \psi_{j r} \leq \hat{p}_{j r}^{0} z_{d_{j}}+\sum_{i \in S_{j}} x_{j i} \quad \forall j \in J \mid D_{j} \neq \emptyset, r=1, \ldots, R \\
& \psi_{j r} \leq \hat{p}_{j i r} u_{j r}+1-x_{j i} \quad \forall j \in N, \forall i \in S_{j}, r=1, \ldots, R \\
& \psi_{j r} \leq \hat{p}_{j i r} z_{d_{j}}+1-x_{j i} \quad \forall j \in N \mid D_{j} \neq \emptyset, \forall i \in S_{j}, r=1, \ldots, R
\end{aligned}
$$

Equations (28) determine the cumulative passability of each site $j$ by summing across the cumulative passability terms $\psi_{j r}$ associated with head height ranges $r$. For each head height interval $\left(\hat{H}_{r}, \hat{H}_{r+1}\right], r=1, \ldots, R$, inequalities (29) and (30) set upper bounds on the cumulative passability value $\psi_{j r}$ when no dam is located at site $j\left(\sum_{i \in S_{j}} x_{j i}=0\right)$, while inequalities (31) and (32) apply if a dam of size $i$ is located at $j\left(x_{j i}=1\right)$. Given that exactly one of the $u_{j r}$ variables will be equal to 1 (i.e., head height must fall within a specific range $\left.\left(\hat{H}_{r}, \hat{H}_{r+1}\right]\right)$, a single pair of constraints, either (29)-(30) or (31)-(32) depending on the dam installation decision, will be binding for each site $j$. Regardless of the dam location decision for site $j$, constraints (29)-(30) and (31)-(32) work in the exact same fashion as (11)-(12) do for the simpler model [HPLP2], in which backwater effects on passability are ignored. More specifically, they form a series of probability chains that iteratively evaluate cumulative barrier passability by starting from the most downstream barrier and progressively moving to barriers upstream.

We note that the above linearization is actually quite general. Even when equation (19) is not strictly a step-wise function, it is possible to approximate a continuous nonlinear curve to any degree of accuracy by introducing a sufficient number of breakpoints $R$ and auxiliary $u_{j r}, \theta_{j r}$, and $\psi_{j t}$ variables and constraints.

\section{Case Study}

\subsection{Background}

A case study of England and Wales will be used to illustrate the benefits of using our proposed framework. We started with a dataset consisting of the location of 25,935 natural (i.e., waterfalls) and artificial (i.e., weirs, dams, barrages, and locks) barriers compiled by the UK Environment Agency (EA, 2010). Each barrier in the EA's database is georeferenced and includes a description of its barrier type and head value. These head 


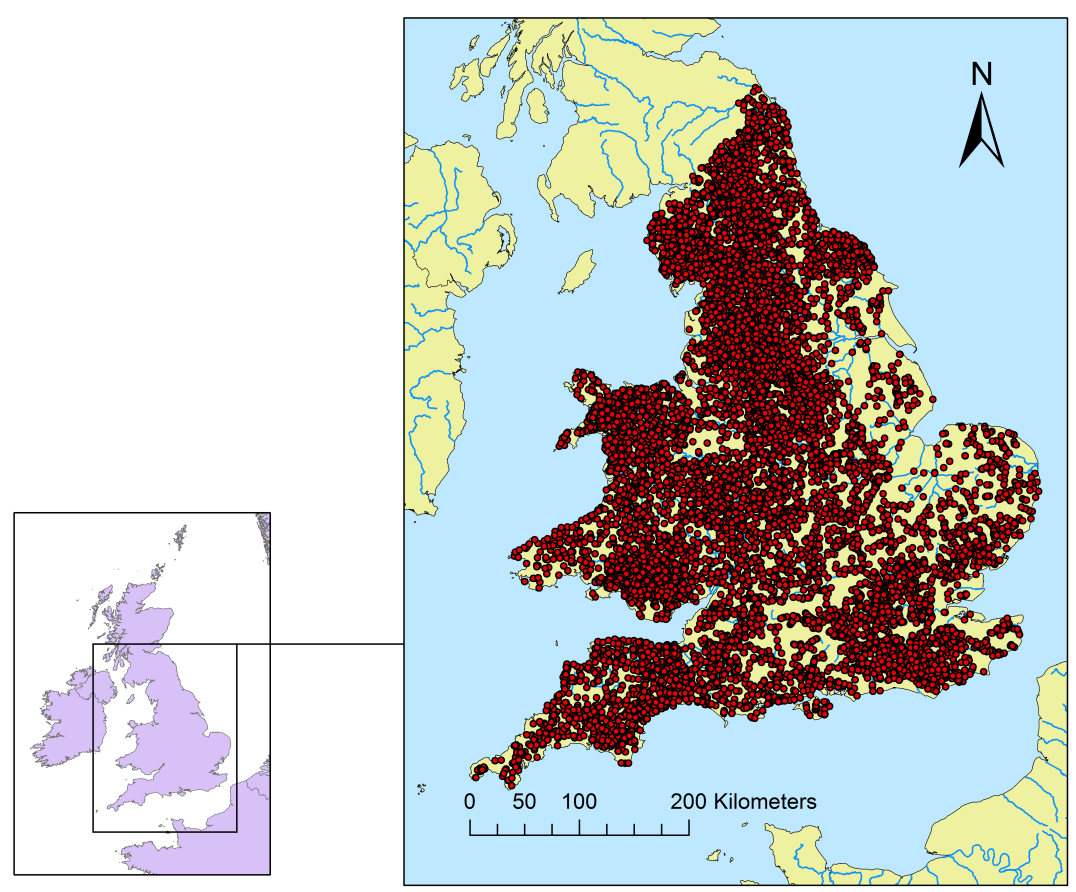

Figure 2: Location of artificial and natural fish barriers across England and Wales.

values correspond to the differences between the upstream and downstream water elevations of the barriers and were obtained from aerial surveys using a combination of Light Detection and Ranging (LIDAR) and Interferometric Synthetic Aperture Radar (IFSAR) remote sensing technology (EA, 2010).

To determine key barrier parameters, including each barrier's immediate downstream barrier $\left(d_{j}\right)$ and net upstream river length $\left(v_{j}\right)$, we used the RivEX toolbox (Hornby, 2014) for ArcGIS 10.2.1. Working off a 1:50,000 scale continuous center-line hydrology layer provided by the UK Centre for Ecology and Hydrology (CEH) (Moore et al., 1994), we first generated a single-threaded river network. The barrier points were subsequently snapped to the river network using a $50 \mathrm{~m}$ snapping distance. This resulted in a final dataset of 14,682 artificial and 4,947 natural barriers, as shown in Figure 2.

Following common practice within England and Wales, we assumed that SHP could only be installed at existing dam/weir sites. We considered three different SHP sizing options. All dams/weirs with head heights up to $5 \mathrm{~m}$ were deemed suitable for the installation of a $5 \mathrm{~m} \mathrm{SHP}$; those with heights between 5 and $10 \mathrm{~m}$ were candidates for a $10 \mathrm{~m}$ SHP. For any dam/weir with a height greater than $10 \mathrm{~m}$, installation of an SHP was assumed to not increase the existing height of the structure. As a conservative estimate (Cyr et al., 2011), we assumed SHPs had a conversion efficiency of $\eta_{j i}=0.7, \forall j, i$.

To determine flow values $\left(Q_{j}\right)$ of each SHP candidate site, we developed a regression model to predict mean 
flow based on mean annual precipitation within the site's upstream catchment area. Mean flow data were obtained for 1,403 georeferenced gauging stations from the UK National River Flow Archive (NRFA). In a series of ArcGIS steps, we delineated the catchment area for each gauging station using $50 \mathrm{~m}$ digital elevation model (DEM), outflow drainage direction, and cumulative catchment area grids provided by CEH. Gauging station catchment areas were then overlaid on a $5 \mathrm{~km} \times 5 \mathrm{~km}$ annual precipitation grid for England and Wales produced from UK MetOffice historical monthly average rainfall grids for the period 1981-2010 (MetOffice, 2014). From this, area-weighted annual precipitation could be determined for each gauging station ( precip $_{j}$ ) and subsequently used to estimate mean flow $\left(Q_{j}\right)$ as follows.

$$
\ln \left(Q_{j}\right)=-8.37+1.05 \ln \left(\text { precip }_{j}\right)
$$

The log-linear model (33) produced a very good fit to the data, with an adjusted $\mathrm{R}^{2}$ of 0.89 . The previous GIS steps were then repeated to calculate a $\operatorname{precip}_{j}$ value for each potential SHP site $j$ and estimate an associated flow volume $Q_{j}$ based on regression model (33).

Potential changes in head height due to the backwater effect of an SHP located downstream $\left(\Delta H_{j k t}\right)$ were determined as follows. Under a gradually varied flow regime, backwater profiles for each SHP site up to the nearest SHP or river confluence point can be found using the "standard step" method, as described in Chadwick et al. (2013). This method allows the evaluation of depth at any specified distance upstream of a structure by dividing the watercourse into equal intervals and then iteratively calculating depth at upstream cross sections by solving an energy balance governing equation (Chow, 1959). The standard step method requires, among other things, information about the slope and channel geometry of each upstream cross section. Slope values were calculated in ArcGIS using the DEM provided by CEH. We assumed that watercourses had a simple rectangular geometry. Stream width was estimated based on a river segment's Strahler stream order. To do this, we determined using RivEX the Strahler order (a gross measure of stream size) for each stream segment in the $\mathrm{CEH}$ river network and then overlaid the locations of 24,130 field measurements of stream width taken across the UK (M. Naura, University of Southampton, pers. comm.) to produce a look-up table of Strahler order versus mean stream width.

Finally, we assumed that SHPs would be fitted with fish passes having a combined upstream/downstream passage efficiency of 0.5. This is broadly in line with the findings of Noonan et al. (2012). For a site where no SHP is installed, passability was assumed to vary with the height of a barrier. Based on protocols developed in SNIFFER (2010) for adult trout, we used the following to determine upstream passability $p$ as function of head height $H$. 


$$
p= \begin{cases}1 & \text { if } H \leq 0.4 \mathrm{~m} \\ 0.6 & \text { if } 0.4 \mathrm{~m}<H \leq 0.6 \mathrm{~m} \\ 0.3 & \text { if } 0.6 \mathrm{~m}<H \leq 1 \mathrm{~m} \\ 0 & \text { if } H>1 \mathrm{~m}\end{cases}
$$

Based on this, we used a set of $R+1=5$ breakpoints to define equation (20), such that $\hat{\mathbf{H}}=\{-6,0.4,0.6,1,75\}$ and $\hat{\mathbf{p}}^{0}=\{1,0.6,0.3,0\}$. The first breakpoint $(-6 \mathrm{~m})$ corresponds to the largest (negative) change in head value due swamping, while the last breakpoint $(75 \mathrm{~m})$ corresponds to the largest head height observed in our dataset.

We acknowledge that a more in-depth case study would include cost information related to the construction of dams and fish passes, as well as the monetary benefits of hydropower production. Unfortunately, this goes beyond the scope of our present study. While fish pass costs can be estimated fairly accurately based on the height of a structure, dam construction costs vary considerably from site to site depending on the structural characteristics of any existing weir and the geology/topology of the surrounding area. Devising realistic cost estimates is thus difficult without conducting extensive field surveys. Moreover, we believe our model is primarily suited to the strategic level needs of environmental/energy planning authorities concerned with where hydropower development should be permitted while limiting impacts on river connectivity. Given this, the main focus of our case study is on analyzing hydropower potential across England and Wales rather than performing a detailed economic analysis of the costs and benefits that would accrue to individual companies (usually privately owned) who would ultimately build and operate hydropower facilities.

\subsection{Results}

The basic model [HPLP1] and the backwater effects model [HPLP3] were both implemented in $\mathrm{C}++$ using CPLEX callable libraries version 12.6. All experiments were performed on the same quad-core Dell OptiPlex 9020 laptop (Intel i7-4770 processor, $3.4 \mathrm{GHz}$ per chip) with 8GB of RAM and running Windows 7 64-bit operating system. Model sizes of [HPLP1] and [HPLP3] for our case study area are reported Table 1.

Before going into our analysis, it is important to point out that river connectivity within England and Wales is heavily impaired by the presence of existing barriers. Only about $3 \%(3,410 \mathrm{~km})$ of the $132,071 \mathrm{~km}$ of potential stream habitat located above barriers is currently accessible to migratory fish. In systems with few existing barriers, minimum accessible habitat requirements would normally ensure that comparatively 
Table 1: Model sizes of [HPLP1] and [HPLP3] for the England and Wales case study area.

\begin{tabular}{cccc}
\hline & \multicolumn{2}{c}{ Variables } & \\
\cline { 2 - 3 } Model & Binary & Continuous & Constraints \\
\hline [HPLP1] & 14,682 & 34,311 & 62,495 \\
[HPLP3] & 93,198 & 299,064 & 524,124 \\
\hline
\end{tabular}

small numbers of dam are installed. In our case study, however, there are nearly 20,000 existing barriers, the majority of which (75\%) are completely impassable. According to model [HPLP3] with $\alpha=0$, up to 14,607 SHPs could be installed across England and Wales, resulting in a maximum hydropower potential of 691.9 MW, while at the same time increase accessible habitat by $229 \%$ to $11,217 \mathrm{~km}$ of river.

To consider a more realistic scenario of hydropower development, we added the following constraint to both [HPLP1] and [HPLP3]:

$$
\sum_{j \in N} \sum_{i \in S_{j}} x_{j i} \leq n
$$

which allowed us to determine what the maximum hydropower production would be if at most $n$ new SHPs were located. In addition, we observed during preliminary experiments that both [HPLP1] and [HPLP3] occasionally selected sites with unrealistically small hydropower potential (i.e., $\ll 1 \mathrm{~kW}$ ), mainly in an attempt to satisfy the minimum accessible habitat requirement (4). Indeed, a quick inspection of the England and Wales dataset reveals that among the 14,682 candidate dam sites, nearly a quarter $(3,557)$ have hydropower potential less than $1 \mathrm{~kW}$. In practice, development of sites with insufficient hydropower potential is difficult to justify on economic grounds. To prevent the selection of low-hydropower sites, therefore, we added the following set of constraints to [HPLP1]:

$$
c x_{j i} \leq w_{j i} \quad j \in N, i \in S_{i}
$$

and an equivalent set of constraints to [HPLP3]:

$$
c x_{j i} \leq \pi_{j i} \quad j \in N, i \in S_{i}
$$

In our implementation, we set constant constant $c=5000$, thus excluding all sites with hydropower potential $<5 \mathrm{~kW}$ (typically termed "pico" hydro scale plants). Adding minimum site-level hydropower constraints (37) to [HPLP3] with constraint (35) non-binding (e.g., $n=14,628$ ) and $\alpha=0$, a total of 7,672 SHPs could 
Table 2: Hydropower potential and accessible habitat for various SHP development scenarios.

\begin{tabular}{|c|c|c|c|c|c|c|}
\hline \multirow[b]{2}{*}{$n$} & \multicolumn{3}{|c|}{ [HPLP1] } & \multicolumn{3}{|c|}{ [HPLP3] } \\
\hline & $\begin{array}{r}\text { Hydropower } \\
(\mathrm{MW})\end{array}$ & $\begin{array}{r}\text { Habitat } \\
(\mathrm{km})\end{array}$ & $\begin{array}{r}\text { Time } \\
(\mathrm{s})\end{array}$ & $\begin{array}{r}\text { Hydropower } \\
(\mathrm{MW})\end{array}$ & $\begin{array}{r}\text { Habitat } \\
(\mathrm{km}) \\
\end{array}$ & $\begin{array}{r}\text { Time } \\
(\mathrm{s})\end{array}$ \\
\hline \multicolumn{7}{|c|}{$\geq 0 \%$ Accessible Habitat Increase $(\alpha=1.0)$} \\
\hline 100 & 174.7 & 3,935 & 4.7 & 174.4 & 4,027 & 234.2 \\
\hline 500 & 368.5 & 4,532 & 4.6 & 365.4 & 4,592 & 161.1 \\
\hline 1,000 & 471.1 & 5,302 & 4.5 & 465.4 & 5,345 & 199.5 \\
\hline \multicolumn{7}{|c|}{$\geq 50 \%$ Accessible Habitat Increase $(\alpha=1.5)$} \\
\hline 100 & 173.2 & 5,119 & 5.9 & 172.9 & 5,119 & 531.7 \\
\hline 500 & 367.9 & 5,145 & 5.5 & 364.9 & 5,116 & 728.9 \\
\hline 1,000 & 471.1 & 5,302 & 4.6 & 465.4 & 5,345 & 216.1 \\
\hline \multicolumn{7}{|c|}{$\geq 100 \%$ Accessible Habitat Increase $(\alpha=2.0)$} \\
\hline 100 & 155.3 & 6,821 & 8.9 & 154.7 & 6,821 & 936.2 \\
\hline 500 & 362.1 & 6,828 & 8.7 & 359.1 & 6,822 & 653.1 \\
\hline 1,000 & 469.4 & 6,827 & 7.6 & 463.7 & 6,821 & 698.4 \\
\hline \multicolumn{7}{|c|}{$\geq 150 \%$ Accessible Habitat Increase $(\alpha=2.5)$} \\
\hline 100 & & - & & 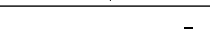 & & \\
\hline 500 & 342.8 & 8,526 & 15.1 & 339.0 & 8,526 & 1518.0 \\
\hline 1,000 & 461.0 & 8,530 & 10.8 & 451.5 & 8,527 & 889.9 \\
\hline \multicolumn{7}{|c|}{$\geq 200 \%$ Accessible Habitat Increase $(\alpha=3.0)$} \\
\hline 100 & - & - & - & - & - & - \\
\hline 500 & 284.5 & 10,231 & 25.3 & 283.9 & 10,231 & 2412.5 \\
\hline 1,000 & 437.6 & 10,232 & 12.6 & 429.9 & 10,231 & 2250.1 \\
\hline
\end{tabular}

A '-' indicates that no feasible solution could be obtained for a given model due to the minimum accessible habitat requirement (4).

be installed, resulting in a maximum hydropower potential of $681.9 \mathrm{MW}$ and a $177 \%$ increase in accessible habitat $(9,439 \mathrm{~km}$ total $)$.

Table 2 reports hydropower potential, accessible habitat, and run times (in CPU seconds) for models [HPLP1] and [HPLP3] given the installation of 100,500 , or 1,000 new SHPs. It is interesting to note that a small subset of candidate sites accounts for a large portion of hydropower generation potential within the study area. For example, according to [HPLP3], almost $25 \%$ of maximum hydropower generation capacity (174.4 MW) can be achieved by siting 100 SHPs, which corresponds to just $0.6 \%$ of all candidate sites. With 1,000 dams (6.8\% of all candidate sites), almost $67 \%$ of maximum hydropower development potential (465.4 MW) can be achieved.

What really stands out from looking at Table 2 is that for our particular study area the installation of hydropower dams actually creates a "win-win" situation with regards to increasing renewable energy production and improving river connectivity. Assuming that an SHP is equipped with even a moderately efficient fish pass ( 0.5 passability), the requirement for a $\geq 100 \%$ increase in accessible habitat (equivalent to more than 6,800 river $\mathrm{km}$ ) could be met according to either model [HPLP1] or [HPLP3]. With 500 or 1,000 SHPs, requirements for either a $\geq 150 \%$ or $\geq 200 \%$ increase in fish habitat would be satisfied. Nonetheless, there are 


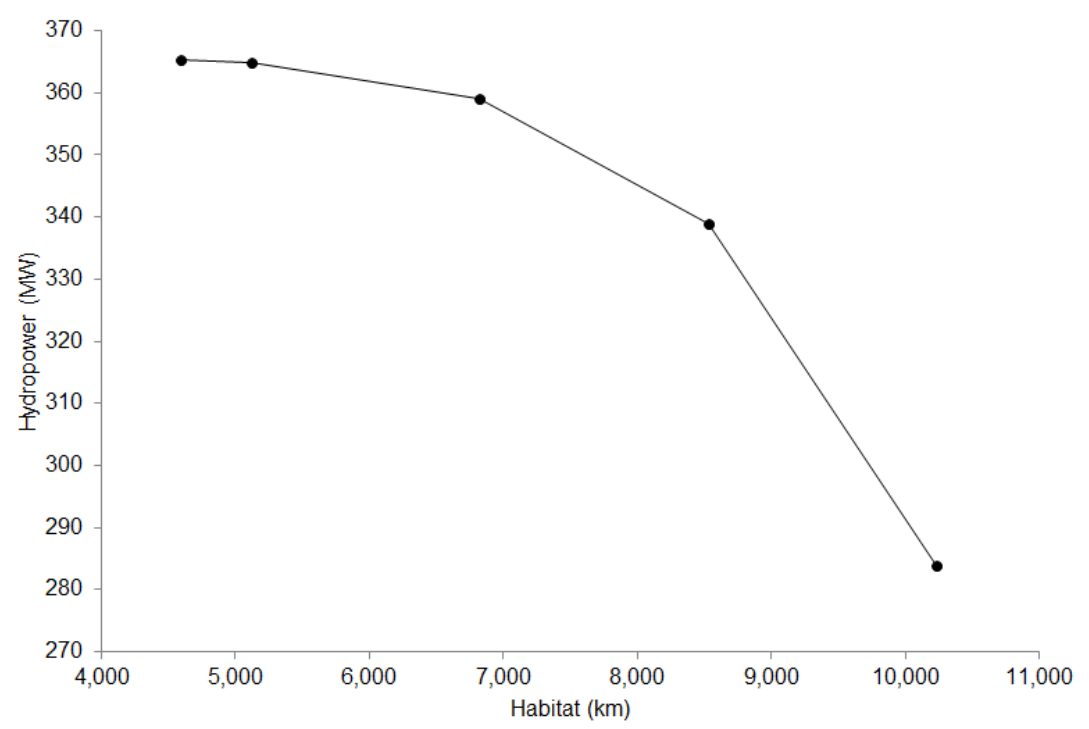

Figure 3: Maximum hydropower potential considering backwater effects (model [HPLP3]) versus total accessible habitat given 500 SHPs.

distinct tradeoffs between increasing fish habitat, on the one hand, and achieving maximum hydropower potential, on the other. Figure 3 shows how hydropower potential deceases with increases in accessible habitat given the location of 500 SHPs.

A comparison of [HPLP1] and [HPLP3] shows that ignoring backwater effects results in a small to moderate overestimation of maximum hydropower potential regardless of accessible habitat requirements. This overestimation goes up as the number of SHPs increases. For example, when no increase in accessible habitat is required, the difference in hydropower potential for [HPLP3] given $100 \mathrm{SHPs}$ is a mere $-0.3 \mathrm{MW}(-0.2 \%)$. When the number of barriers increases to 1,000 , however, there is a $-5.7 \mathrm{MW}(-1.2 \%)$ difference in hydropower for [HPLP3]. The largest difference (-9.5 MW) is observed for 1,000 dams and a $\geq 150 \%$ increase in accessible habitat requirement.

What is also clear from looking at Table 2 is that including backwater effects can result in an appreciable increase in solution time. Regardless of the number of dams or accessible habitat requirements, [HPLP1] can be solved in a matter of seconds to 10s of seconds. For [HPLP3], times vary from several minutes (100 SHPs and $\mathrm{a} \geq 0 \%$ increase in accessible habitat) to over 40 minutes (500 SHPs and a $\geq 200 \%$ increase in accessible habitat).

Table 3 shows how hydropower potential varies for models [HPLP1] and [HPLP3] with and without backwater effects included (i.e., by plugging solutions from [HPLP1] into [HPLP3] and vice versa). It is interesting to note that in spite of the relatively modest backwater effects predicted for our case study area, the vast majority of solutions to [HPLP1] (10 out of 13) are infeasible with respect to the non-swamping constraints 
Table 3: Variation in hydropower potential (in MW) for models [HPLP1] and [HPLP3] with and without backwater effects included.

\begin{tabular}{|c|c|c|c|c|}
\hline \multirow[b]{2}{*}{$n$} & \multicolumn{2}{|c|}{ Solutions to [HPLP1] } & \multicolumn{2}{|c|}{ Solutions to [HPLP3] } \\
\hline & Without Backwater & With Backwater & Without Backwater & With Backwater \\
\hline \multicolumn{5}{|c|}{$\geq 0 \%$ Accessible Habitat Increase $(\alpha=1.0)$} \\
\hline 100 & 174.7 & 173.6 & 174.4 & 174.4 \\
\hline 500 & 368.5 & Infeas. & 365.4 & 365.4 \\
\hline 1000 & 471.1 & Infeas. & 467.1 & 465.4 \\
\hline \multicolumn{5}{|c|}{$\geq 50 \%$ Accessible Habitat Increase $(\alpha=1.5)$} \\
\hline 100 & 173.2 & 172.1 & 172.9 & 172.9 \\
\hline 500 & 367.9 & Infeas. & $364.9 *$ & 364.9 \\
\hline 1000 & 471.1 & Infeas. & 467.1 & 465.4 \\
\hline \multicolumn{5}{|c|}{$\geq 100 \%$ Accessible Habitat Increase $(\alpha=2.0)$} \\
\hline 100 & 155.3 & 154.2 & 154.7 & 154.7 \\
\hline 500 & 362.1 & Infeas. & $359.1^{*}$ & 359.1 \\
\hline 1000 & 469.4 & Infeas. & $465.5^{*}$ & 463.7 \\
\hline \multicolumn{5}{|c|}{$\geq 150 \%$ Accessible Habitat Increase $(\alpha=2.5)$} \\
\hline 100 & - & - & - & - \\
\hline 500 & 342.8 & Infeas. & $339.0^{*}$ & 339.0 \\
\hline 1000 & 461.0 & Infeas. & $453.0^{*}$ & 451.5 \\
\hline \multicolumn{5}{|c|}{$\geq 200 \%$ Accessible Habitat Increase $(\alpha=3.0)$} \\
\hline 100 & - & - & - & - \\
\hline 500 & 284.5 & Infeas. & $283.9^{*}$ & 283.9 \\
\hline 1000 & 437.6 & Infeas. & $431.0^{*}$ & 429.9 \\
\hline
\end{tabular}

A '-' indicates that no feasible solution to the original model could be obtained due to the minimum accessible habitat requirement (4). For solutions to [HPLP1], 'Infeas.' indicates that one or more swamping constraints (18) are violated when backwater effects are included. For solutions to [HPLP3], a ${ }^{*}$ ' indicates that the minimum accessible habitat requirement (4) is not strictly satisfied when backwater effects are ignored.

(18), meaning one or more dams would end up being submerged due to the presence of a downstream dam. It also interesting that more than half of [HPLP3] solutions (7 out of 13) would be technically infeasible, due to violations of the minimum accessible habitat requirement (4), if backwater effects were ignored. This occurs because small but material increases in accessible habitat (0.1-0.9\%) are produced when passability is calculated dynamically as function of head height (via constraints (20)-(32)), thus allowing accessible habitat requirements to just be met by solutions to [HPLP3].

Table 4 reports basic statistics about initial head height, Strahler stream order, and distance to river mouth of SHP sites selected by [HPLP3] for various minimum accessible habitat requirements. Column "All" refers to all 14,682 candidate sites. What stands out is that low-head dam/weir sites $(\leq 5 \mathrm{~m})$ are far and away the preferred choice for siting SHPs. Such sites make up roughly $87 \%$ of all artificial barriers, but account for no less than $95 \%$ of selected sites, regardless of the specific number of SHPs sited or minimum requirements on accessible habitat.

Another observation is that selected SHPs tend be located on high-order streams. This is not at all surprising given that stream order is normally a very good proxy for flow $(Q)$ and, in turn, hydropower potential $(\pi)$. 


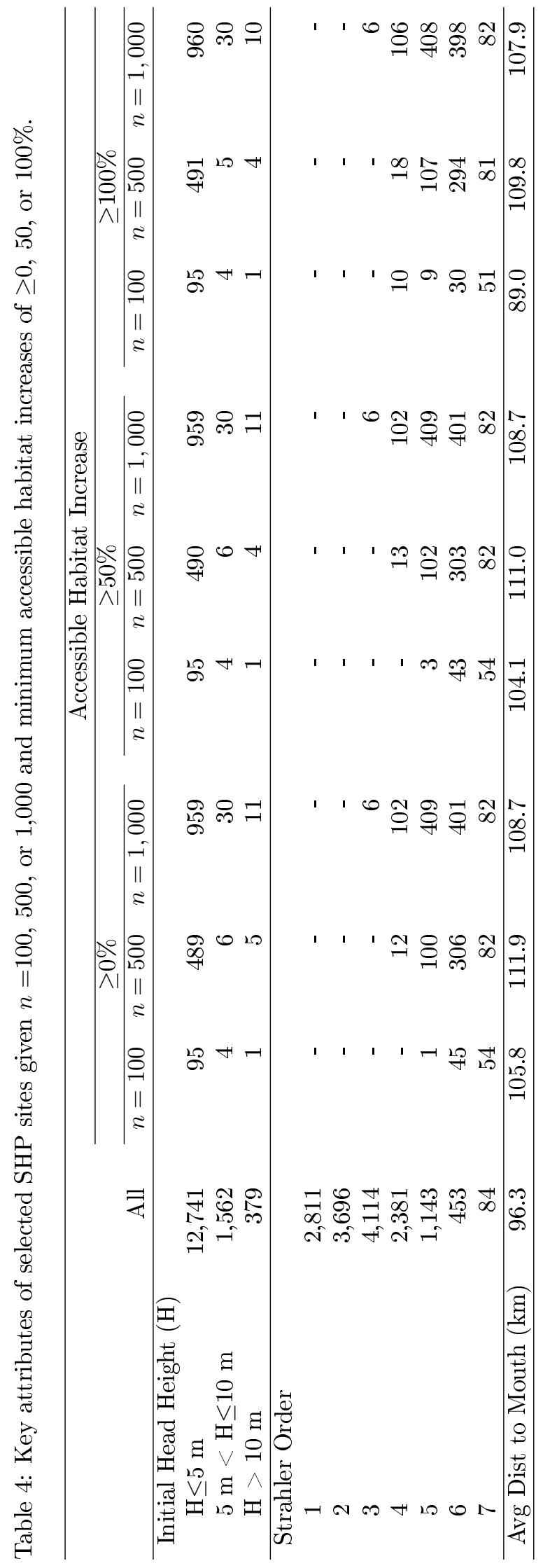




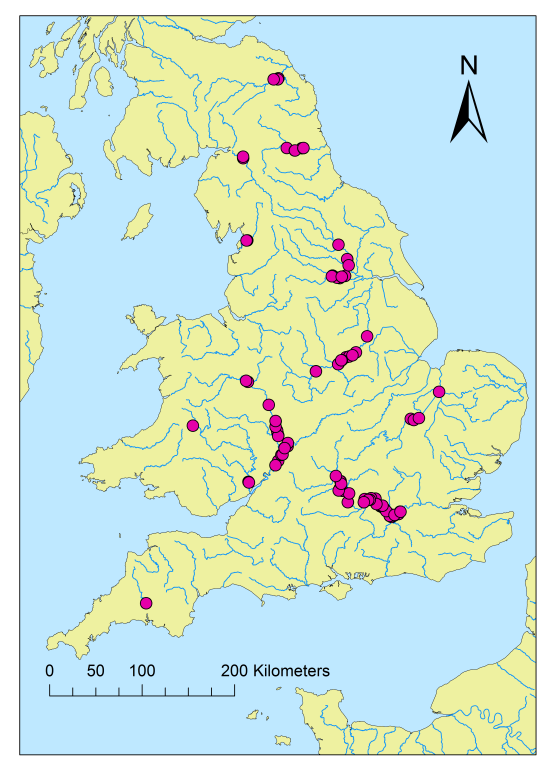

(a)

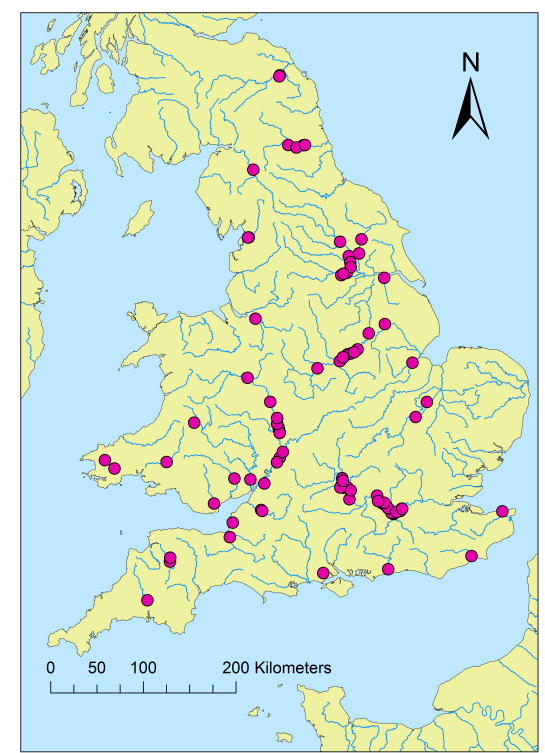

(b)

Figure 4: Solutions to the backwater effects model [HPLP3] with 100 SHPs given a $\geq 0 \%$ (a) and $\geq 100 \%$ (b) increase in accessible habitat.

Looking at the various solutions in Table 4, SHPs are never located on order 1-2 streams nor even on order 3 streams unless 1,000 SHPs are located. Instead, the vast majority (89-100\%) of SHPs are located on order

\section{5-7 streams.}

What is more interesting is that for any given number of SHP sites, model [HPLP3] selects locations that are both closer to the river mouth and on lower order streams as the minimum accessible habitat requirement increases. Given $100 \mathrm{SHPs}$, for example, average distance to mouth decreases by $16.8 \mathrm{~km}$ (from $105.8 \mathrm{~km}$ to $89.0 \mathrm{~km}$ ) when the accessible habitat requirement changes from $\geq 0 \%$ to $\geq 100 \%$. At the same time, the number of sites selected on mid order 3-4 streams goes from 0 to 10.

Locating SHPs fitted with fish passes closer to the river mouth makes perfect sense if the primary aim is to increase accessible river habitat; barriers closer to the sea will generally disrupt longitudinal river connectivity the most. However, within a given river catchment, stream order and distance to mouth are normally inversely related, with low order streams found higher up in the catchment (i.e., further away from the river mouth). All thing being equal then, the a priori hypothesis would be that sites on mainstem, high-order rivers that are also close to the sea should be preferred.

This apparent contradiction is explained by the shifting spatial pattern of SHP location. Inspection of Figure 4 shows that SHPs are predominately located on major, high-order rivers, such as the Thames, the Severn, the Trent, the Aire, the Tyne, and their major tributaries when habitat requirements are less stringent (i.e., given a $0 \%$ or $100 \%$ minimum increase in accessible habitat). However, when habitat requirements are at 
the high end (i.e., given a 100\% minimum increase in accessible habitat), many more SHPs are located on smaller, middle-order rivers at sites closer to the sea. Ultimately, what this shows is that balancing tradeoffs between hydropower and river connectivity is a complex issue. Depending on one's aims, the best locations for hydropower development can vary considerably.

\section{Conclusions}

Proposals to install hydropower dams inevitably raise conflict between the need for renewable energy production on the one hand and the desire for maintaining healthy, well-connected river ecosystems on the other. In this paper, we present a suite of optimization based tools for locating small hydropower dams in an environmentally friendly manner. Importantly, we take into account the backwater effects that dams have on both hydropower and fish passability at nearby upstream sites. Through a series of linearization steps, we manage to formulate a mixed-integer linear programing model.

The usefulness of our framework is demonstrated with a case study from England and Wales. We find that our backwater effects model is highly scalable. With more than 14,000 candidate sites, model [HPLP3] could still solve in less than hour, regardless of accessible habitat requirements. One key result is that a comparatively small number of sites accounts for a large portion of hydropower potential within the study area. Installation of just 100 SHPs can produce $25 \%$ of maximum hydropower generation capacity, while $67 \%$ of maximum hydropower can be achieved by siting 1,000 SHPs. More importantly, given the heavily impaired state of river connectivity across England and Wales, installation of SHP can actually create a win-win result yielding both increased hydropower and improved river connectivity if SHPs are fitted with even moderately effective fish passes. We also observe that optimal SHP locations vary depending on how stringent requirements are for increasing amounts of accessible river habitat. SHPs are predominately located in large river systems when habitat requirements are low to moderate and more frequently in smaller river systems when habitat requirements are high.

In our case study, we found that backwater effects had only a modest influence on maximum hydropower potential and accessible river habitat. It is important to emphasize, however, that the extent of backwater effects will be context dependent, determined in large part based on the size and spacing of dams and the geometry of river channels. Across England and Wales, river connectivity and water surface profiles are already heavily impacted by a large number of existing barriers. Moreover, we assumed that 1) hydropower facilities could only be installed at existing weirs and 2) increases in head height were restricted to $\leq 5$ m. Consequently, even though spacing among candidate SHP sites is tight along some stretches of river, 
backwater effects were not as pronounced compared to a situation where dams could be constructed at "greenfield" sites (i.e., where barriers are not currently present). In addition, many river channels across England and Wales have relatively steep slopes (critical depth > normal depth), which causes a backwater curve to reduce in length. Indeed, for most SHP candidate sites in our study, the backwater curve did not extend to any immediate upstream sites due to the steepness of the channel slope. In other study areas, where such conditions do not hold, we would expect backwater effects to have a much larger impact on hydropower potential and accessible habitat.

Regardless of the relative influence of backwater effects on hydropower and river connectivity, our results clearly show the benefit of taking backwater effects into account. Solutions to our simpler model [HPLP1], which ignored backwater effects, frequently produced infeasible solutions in which a dam would be entirely swamped due to the presence of a nearby dam downstream. Hence, even though our more complex model [HPLP3] had a marked overhead in terms of solution times, it invariably produced more realistic solutions that did not violate non-swamping constraints.

There are a number of ways in which our models could be extended. For example, we have focused on migratory fish with a diadromous life-cycle history (i.e., where fish travel between fresh water and the sea). This is not the only type of migratory behavior. Our modeling framework could be easily adapted to handle potadromous dispersal patterns (Cote et al., 2009; O'Hanley et al., 2013b), where fish regularly move between different sections within a river network over the course of a year. One could also take a more in-depth approach by incorporating spatially explicit fish population dynamics (Ziv et al., 2012).

Whereas we focused on locating smaller run-of-river type hydropower dams, another area for future research might include focusing on larger, reservoir type dams. As the name implies, such dams create large reservoirs upstream (e.g., Lake Meade behind Hoover dam). Their main benefit is the much greater hydropower that can be generated. On the other hand, their impacts go well beyond disrupting river connectivity; they can significantly reduce sediment flow, dampen seasonal flow variation (aka the "natural hydrograph"), cause loss of riparian and terrestrial habitat (due to submersion), and promote the spread of aquatic invasive species (Stanford et al., 1996). At the same time, large reservoir dams can deliver additional socio-economic benefits that run-of-river dams at best only partially provide, such as water storage/supply, flood protection, fishing, and recreational opportunities (Kuby et al., 2005; Zheng et al., 2009). Both the socio-economic benefits and environmental costs of dams can be estimated fairly easily using established market and non-market valuation techniques (MacDonald et al., 2011), suggesting that one might consider integrating adopting a bio-economic analysis framework to optimize large hydropower dam location decisions.

Finally, one could take a more integrated approach that considers hydropower dam placement together with 
artificial barrier mitigation decisions. Such a model would allow for offsetting actions in which reduced passability due the installation of hydropower facilities may be compensated for by improvements in passability at other locations (Owen and Apse, 2015). With such a framework, it would be possible to determine where best to carry out barrier mitigation, namely at newly installed hydropower dams or at other existing structures that more heavily impact connectivity. These sorts of considerations are important in many heavily developed river systems, such as the US, Canada, and Europe where conflict often arrises between proponents on each side of the renewable energy generation versus river connectivity restoration debate.

There are a number of ways in which our models could be extended. For example, we have focused on migratory fish with a diadromous life-cycle history (i.e., where fish travel between fresh water and the sea). This is not the only type of migratory behavior. Our modeling framework could be easily adapted to handle potadromous dispersal patterns (Cote et al., 2009; O'Hanley et al., 2013b), where fish regularly move between different sections within a river network over the course of a year. One could also take a more in-depth approach by incorporating spatially explicit fish population dynamics (Ziv et al., 2012).

Whereas we focused on locating smaller run-of-river type hydropower dams, another area for future research might include focusing on larger, reservoir type dams. As the name implies, such dams create large reservoirs upstream (e.g., Lake Meade behind Hoover dam). Their main benefit is the much higher hydropower potential. On the other hand, their impacts go well beyond disrupting river connectivity; they can significantly reduce sediment flow, dampen seasonal flow variation (aka the "natural hydrograph"), cause loss of riparian and terrestrial habitat (due to submersion), and promote the spread of aquatic invasive species (Stanford et al., 1996). At the same time, large reservoir dams can deliver additional socio-economic benefits that run-of-river dams at best only partially provide, such as water storage/supply, flood protection, fishing, and recreational opportunities (Kuby et al., 2005; Zheng et al., 2009). Both the socio-economic benefits and environmental costs of dams can be estimated using established market and non-market valuation techniques (MacDonald et al., 2011), suggesting that one might consider adopting a bio-economic analysis framework to optimize large hydropower dam location decisions.

Finally, one could take a more integrated approach that considers hydropower dam placement together with artificial barrier mitigation decisions. Such a model would allow for offsetting actions in which reduced passability due the installation of hydropower facilities may be compensated for by improvements in passability at other locations (Owen and Apse, 2015). With such a framework, it would be possible to determine where best to carry out barrier mitigation, namely at newly installed hydropower dams or at other existing structures that more heavily impact connectivity. These sorts of considerations are important in many heavily developed river systems, such as the US, Canada, and Europe where conflict often arises between proponents 
on each side of the renewable energy generation versus river connectivity restoration debate.

\section{Acknowledgments}

C. Ioannidou was supported by the UK Engineering and Physical Sciences Research Council (EPSRC). This support is gratefully acknowledged. The authors are further indebted to the following people and organizations for the provision of data used in the England and Wales case study: Jim Gregory from the Environment Agency, Caroline Cowan from the Center for Ecology and Hydrology, Marc Naura, the National River Flow Archive, and the MetOffice. Finally, we wish to thank three anonymous referees and the associate editor for helpful comments made on an earlier draft of this paper.

\section{References}

Bednarek, A. T. (2001). Undamming rivers a review of the ecological impacts of dam removal. Environmental Management, 27(6):803-814.

Chadwick, A., Morfett, J., and Borthwick, M. (2013). Hydraulics in civil and environmental engineering. CRC Press, Boca Raton (FL), USA.

Chang, S.-Y., Liaw, S.-L., Railsback, S. F., and Sale, M. J. (1992). Modeling alternatives for basin-level hydropower development: 1. optimization methods and applications. Water resources research, 28(10):25812590.

Chow, V. T. (1959). Open-channel hydraulics. McGraw-Hill, New York (NY), USA.

Coskun, H. G., Alganci, U., Eris, E., Agiralioglu, N., Cigizoglu, H. K., Yilmaz, L., and Toprak, Z. F. (2010). Remote sensing and GIS innovation with hydrologic modelling for hydroelectric power plant (HPP) in poorly gauged basins. Water Resources Management, 24(14):3757-3772.

Cote, D., Kehler, D. G., Bourne, C., and Wiersma, Y. F. (2009). A new measure of longitudinal connectivity for stream networks. Landscape Ecology, 24(1):101-113.

Cyr, J.-F., Landry, M., and Gagnon, Y. (2011). Methodology for the large-scale assessment of small hydroelectric potential: Application to the Province of New Brunswick (Canada). Renewable Energy, 36(11):29402950. 
DECC (2010). National renewable energy action plan for the United Kingdom: Article 4 of the Renewable Energy Directive 2009/28/EC. www.gov.uk/government/uploads/system/uploads/attachment_data/ file/47871/25-nat-ren-energy-action-plan.pdf. Accessed 16/06/2016.

Dudhani, S., Sinha, A., and Inamdar, S. (2006). Assessment of small hydropower potential using remote sensing data for sustainable development in india. Energy Policy, 34(17):3195-3205.

EA (2010). Mapping hydropower opportunities and sensitivities in England and Wales. Technical report, Environment Agency (EA), Bristol, UK.

ESHA (2012). Small hydropower roadmap: Condensed research data for EU-27. Technical report, European Small Hydropower Association (ESHA), Brussels, Belgium.

HM Government (2009a). The UK low carbon transition plan: National strategy for climate and energy. www.gov.uk/government/uploads/system/uploads/attachment_data/file/228752/ 9780108508394 .pdf. Accessed 16/06/2016.

HM Government (2009b). The UK renewable energy strategy. www.gov.uk/government/uploads/system/ uploads/attachment_data/file/228866/7686.pdf. Accessed 16/06/2016.

Hornby, D. (2014). RivEX (Version 10.19) [software]. www.rivex.co.uk. Accessed 25/04/2014.

Kemp, P. and O'Hanley, J. (2010). Procedures for evaluating and prioritising the removal of fish passage barriers: a synthesis. Fisheries Management and Ecology, 17(4):297-322.

Kuby, M. J., Fagan, W. F., ReVelle, C. S., and Graf, W. L. (2005). A multiobjective optimization model for dam removal: an example trading off salmon passage with hydropower and water storage in the willamette basin. Advances in Water Resources, 28(8):845-855.

Kusre, B., Baruah, D., Bordoloi, P., and Patra, S. (2010). Assessment of hydropower potential using gis and hydrological modeling technique in kopili river basin in assam (india). Applied Energy, 87(1):298-309.

Larentis, D. G., Collischonn, W., Olivera, F., and Tucci, C. E. (2010). Gis-based procedures for hydropower potential spotting. Energy, 35(10):4237-4243.

Lee, R., Brizzee, J., Cherry, S., and Hall, D. G. (2008). Virtual hydropower prospecting: A foundation for water energy resource planning and development. Journal of Map \& Geography Libraries, 4(2):336-347.

Lucas, M. and Baras, E. (2001). Migration of freshwater fishes. Blackwell Science, Oxford, UK. 
MacDonald, D., Morrison, M., Rose, J., and Boyle, K. (2011). Valuing a multistate river: The case of the River Murray. The Australian Journal of Agricultural and Resource Economics, 55:374-392.

MetOffice (2014). Ukcp09: $5 \mathrm{~km}$ gridded data - monthly averages. http://www.metoffice.gov.uk/ climatechange/science/monitoring/ukcp09/download/longterm/fivekm_monthly.html. Accessed $10 / 01 / 2014$.

Moore, R., Morris, D., and Flavin, R. (1994). Sub-set of UK digital 1:50,000 scale river centre-line network. Technical report, NERC, Institute of Hydrology, Wallingford, UK.

Neeson, T., Ferris, M., Diebel, M., Doran, P., O'Hanley, J., and McIntyre, P. (2015). Enhancing ecosystem restoration efficiency through spatial and temporal coordination. Proceedings of the National Academy of Sciences USA, 112(19):6236-6241.

Noonan, M., Grant, J., and Jackson, C. (2012). A quantitative assessment of fish passage efficiency. Fish and Fisheries, 13(4):450-464.

O'Hanley, J. R. (2011). Open rivers: Barrier removal planning and the restoration of free-flowing rivers. Journal of environmental management, 92(12):3112-3120.

O'Hanley, J. R., Scaparra, M. P., and Garca, S. (2013a). Probability chains: A general linearization technique for modeling reliability in facility location and related problems. European Journal of Operational Research, 230(1):63-75.

O'Hanley, J. R. and Tomberlin, D. (2005). Optimizing the removal of small fish passage barriers. Environmental Modeling and Assessment, 10(2):85-98.

O’Hanley, J. R., Wright, J., Diebel, M., Fedora, M. A., and Soucy, C. L. (2013b). Restoring stream habitat connectivity: A proposed method for prioritizing the removal of resident fish passage barriers. Journal of environmental management, 125:19-27.

Owen, D. and Apse, C. (2015). Trading dams. UC Davis Law Review, 48(3):1043-1109.

Paulsen, C. M. and Wernstedt, K. (1995). Cost-effectiveness analysis for complex managed hydrosystems: an application to the columbia river basin. Journal of Environmental Economics and Management, 28(3):388400.

Ramachandra, T., Kumar, R., Jha, S., Vamsee, K., and Shruthi, B. (2004). Spatial decision support system for assessing micro, mini and small hydel potential. Journal of Applied Sciences, 4(4):596-604. 
Rojanamon, P., Chaisomphob, T., and Bureekul, T. (2009). Application of geographical information system to site selection of small run-of-river hydropower project by considering engineering/economic/environmental criteria and social impact. Renewable and Sustainable Energy Reviews, 13(9):2336-2348.

Roni, P., Beechie, T. J., Bilby, R. E., Leonetti, F. E., Pollock, M. M., and Pess, G. R. (2002). A review of stream restoration techniques and a hierarchical strategy for prioritizing restoration in pacific northwest watersheds. North American Journal of Fisheries Management, 22(1):1-20.

SNIFFER (2010). WFD111 (2a) coarse resolution rapid-assessment methodology to assess obstacles to fish migration. Field manual level A assessment. Technical report, Scotland \& Northern Ireland Forum for Environmental Research, Edinburgh, UK.

Stanford, J. A., Ward, J., Liss, W. J., Frissell, C. A., Williams, R. N., Lichatowich, J. A., and Coutant, C. C. (1996). A general protocol for restoration of regulated rivers. Regulated Rivers: Research \& Management, $12(4-5): 391-413$.

Winston, W. (2004). Operations research: Applications and algorithms. Duxbury Press, Belmont (CA), USA, 4 edition.

Yi, C.-S., Lee, J.-H., and Shim, M.-P. (2010). Site location analysis for small hydropower using geo-spatial information system. Renewable Energy, 35(4):852-861.

Zheng, P. Q. and Hobbs, B. F. (2012). Multiobjective portfolio analysis of dam removals addressing dam safety, fish populations, and cost. Journal of Water Resources Planning and Management, 139(1):65-75.

Zheng, P. Q., Hobbs, B. F., and Koonce, J. F. (2009). Optimizing multiple dam removals under multiple objectives: linking tributary habitat and the lake erie ecosystem. Water Resources Research, 45(12):W12417.

Ziv, G., Baran, E., Nam, S., RodrÃguez-Iturbe, I., and Levin, S. A. (2012). Trading-off fish biodiversity, food security, and hydropower in the mekong river basin. Proceedings of the National Academy of Sciences, 109(15):5609-5614. 